\title{
Design and Control of Warehouse Order Picking: a literature review
}

\author{
René de Koster, Tho Le-Duc and Kees Jan Roodbergen
}

\begin{tabular}{|l|l|}
\hline \multicolumn{2}{|l|}{ ERIM REPORT SERIES RESEARCH IN MANAGEMENT } \\
\hline ERIM Report Series reference number & ERS-2006-005-LIS \\
\hline Publication & January 2006 \\
\hline Number of pages & 30 \\
\hline Persistent paper URL & \\
\hline Email address corresponding author & rkoster@rsm.nl \\
\hline Address & Erasmus Research Institute of Management (ERIM) \\
& RSM Erasmus University / Erasmus School of Economics \\
& Erasmus Universiteit Rotterdam \\
& P.O.Box 1738 \\
& 3000 DR Rotterdam, The Netherlands \\
& Phone: $\quad+31104081182$ \\
& Fax: $\quad+31104089640$ \\
& Email: info@erim.eur.nl \\
& Internet: $\quad$ www.erim.eur.nl \\
\hline
\end{tabular}

Bibliographic data and classifications of all the ERIM reports are also available on the ERIM website: www.erim.eur.nl 


\section{ERASMUS RESEARCH INSTITUTE OF MANAGEMENT}

\section{REPORT SERIES \\ RESEARCH IN MANAGEMENT}

\begin{tabular}{|c|c|}
\hline \multicolumn{2}{|c|}{ ABSTRACT AND KEYWORDS } \\
\hline Abstract & $\begin{array}{l}\text { Order picking has long been identified as the most labour-intensive and costly activity for almost } \\
\text { every warehouse; the cost of order picking is estimated to be as much as } 55 \% \text { of the total } \\
\text { warehouse operating expense. Any underperformance in order picking can lead to unsatisfactory } \\
\text { service and high operational cost for its warehouse, and consequently for the whole supply } \\
\text { chain. In order to operate efficiently, the orderpicking process needs to be robustly designed and } \\
\text { optimally controlled. This paper gives a literature overview on typical decision problems in design } \\
\text { and control of manual order-picking processes. We focus on optimal (internal) layout design, } \\
\text { storage assignment methods, routing methods, order batching and zoning. The research in this } \\
\text { area has grown rapidly recently. Still, combinations of the above areas have hardly been } \\
\text { explored. Order-picking system developments in practice lead to promising new research } \\
\text { directions. }\end{array}$ \\
\hline Free Keywords & Order picking, Warehouse Management, Logistics \\
\hline Availability & $\begin{array}{l}\text { The ERIM Report Series is distributed through the following platforms: } \\
\text { Academic Repository at Erasmus University (DEAR), DEAR ERIM Series Portal } \\
\text { Social Science Research Network (SSRN), SSRN ERIM Series Webpage } \\
\text { Research Papers in Economics (REPEC), REPEC ERIM Series Webpage }\end{array}$ \\
\hline Classifications & $\begin{array}{l}\text { The electronic versions of the papers in the ERIM report Series contain bibliographic metadata } \\
\text { by the following classification systems: } \\
\text { Library of Congress Classification, (LCC) LCC Webpage } \\
\text { Journal of Economic Literature, (JEL), JEL Webpage } \\
\text { ACM Computing Classification System CCS Webpage } \\
\text { Inspec Classification scheme (ICS), ICS Webpage }\end{array}$ \\
\hline
\end{tabular}




\title{
Design and control of warehouse order picking: a literature review
}

\author{
René de Koster ${ }^{1}$, Tho Le-Duc, Kees Jan Roodbergen \\ RSM Erasmus University \\ P.O. box 1738, 3000 DR Rotterdam, The Netherlands \\ phone: +31-10-4081719 \\ fax: $+31-10-4089014$
}

${ }^{1}$ corresponding author, rkoster@rsm.nl 


\title{
Design and control of warehouse order picking: a literature review
}

\begin{abstract}
Order picking has long been identified as the most labour-intensive and costly activity for almost every warehouse; the cost of order picking is estimated to be as much as 55\% of the total warehouse operating expense. Any underperformance in order picking can lead to unsatisfactory service and high operational cost for its warehouse, and consequently for the whole supply chain. In order to operate efficiently, the orderpicking process needs to be robustly designed and optimally controlled. This paper gives a literature overview on typical decision problems in design and control of manual order-picking processes. We focus on optimal (internal) layout design, storage assignment methods, routing methods, order batching and zoning. The research in this area has grown rapidly recently. Still, combinations of the above areas have hardly been explored. Order-picking system developments in practice lead to promising new research directions.
\end{abstract}

Keywords: Order picking; Warehouse management; Logistics

\section{Introduction}

As more companies look to cut costs and improve productivity within their warehouses and distribution centres, picking has come under increased scrutiny. Order picking - the process of retrieving products from storage (or buffer areas) in response to a specific customer request - is the most labour-intensive operation in warehouses with manual systems, and a very capital-intensive operation in warehouses with automated systems (Goetschalckx and Ashayeri 1989, Drury 1988, Tompkins et al. 2003). For these reasons, warehousing professionals consider order picking as the highest-priority area for productivity improvements.

Several recent trends both in manufacturing and distribution have made the order-picking design and management become more important and complex. In manufacturing, there is a move to smaller lot-sizes, point-of-use delivery, order and product customisation, and cycle time reductions. In distribution logistics, in order to serve customers, companies tend to accept late orders while providing rapid and timely delivery within tight time windows (thus the time available for order picking becomes shorter). Many smaller warehouses are being replaced by fewer large warehouses to realise economies of scale. In these large warehouses, the daily pick volume is large and the available time window is short. In order to be more responsive to customers, many companies have adopted a postponement strategy (Van Hoek 2001) leading to various value-adding activities (like kitting, labelling, product or order assembly, customised packaging or palletisation) that take place in the distribution centre and which have to be scheduled and integrated in the order-picking process. Warehouses are also involved in recovering products, materials, and product carriers from customers in order to redistribute them to other customers, recyclers, and original-equipment manufacturers (De Koster et al., 2002). 
The organisation of order-picking operations immediately impacts the distribution centre's and thereby the supply chain's performance. Between the time an order is released to the warehouse and the time it takes to reach its destination, there is ample opportunity for errors in both accuracy and completeness, not to mention time lost. There is also room for improvement. Industry has come up with innovative solutions, making it possible to attain productivity up to 1,000 picks per person hour. Science is also progressing rapidly. Over the last decades, many papers have appeared studying order picking processes. New problems have been studied and new models have been developed. Still, there is a gap between practice and academic research, since not all new picking methods have been studied and the optimal combinations of layout, storage assignment, order clustering, order release method, picker routing and order accumulation have been addressed to a minor extent only. This paper presents a systematic overview of these recent developments in academic literature. We structure typical decision problems in design and control of order-picking processes by focusing on optimal (internal) layout design, storage assignment methods, routing methods, order batching, and zoning. Several areas appear to have received only little attention from researchers. Innovations from practice also lead to new research challenges.

The remainder of the paper is organised as follows. In the next section, we briefly highlight warehouse missions and functions and give an overview of order-picking systems. In Sections 3 to 8, we review recent literature on design and control of order-picking processes, focussing on layout design, storage assignment, batching, picker routing, and order accumulation. We conclude and discuss potential research directions in Section 8.

\section{Warehouses and order picking}

According to ELA/AT Kearney (2004), warehousing contributed to about 20\% of the surveyed companies' logistics costs in 2003 (other activities distinguished are value added services, administration, inventory costs, transportation and transport packaging). Warehouses apparently form an important part of a firm's logistics system. They are commonly used for storing or buffering products (raw materials, goods-in-process, finished products) at and between points of origin and points of consumption. The term 'warehouse' is used if the main function is buffering and storage. If additionally distribution is a main function, the term 'distribution centre' is commonly used, whereas 'transhipment', 'cross-dock', or 'platform' centre are often used if storage hardly plays a role. As we focus on order picking from inventory, we use the term 'warehouse' throughout the paper. Lambert et al. (1998) state that more than 750,000 warehouse facilities exist worldwide, including state-of-art, professionally managed warehouses, as well as company stockrooms and self-store facilities. Warehouses often involve large investments and operating costs (e.g. cost of land, facility equipment, labour ...). So, why do warehouses exist? According to Lambert et al. (1998) they contribute to a multitude of the company’s missions, like

- Achieving transportation economies (e.g. combine shipment, full-container load).

- Achieving production economies (e.g. make-to-stock production policy).

- Taking advantage of quality purchase discounts and forward buys.

- Supporting the firm's customer service policies.

- Meeting changing market conditions and uncertainties (e.g. seasonality, demand fluctuations, competition).

- Overcoming the time and space differences that exist between producers and customers.

- Accomplishing least total cost logistics commensurate with a desired level of customer service.

- Supporting the just-in-time programs of suppliers and customers. 
- Providing customers with a mix of products instead of a single product on each order (i.e. consolidation).

- Providing temporary storage of material to be disposed or recycled (i.e. reverse logistics).

- Providing a buffer location for trans-shipments (i.e. direct delivery, cross-docking).

In some special situations (e.g. lean manufacturing, 'virtual' inventory, cross-docking), storage functions in a supply chain can be reduced. But, in almost all supply chains, raw materials, parts, and product inventories still need to be stored or buffered, implying that warehouses are needed and play a critical role in the companies' logistics success.

\section{Warehouse flows}

Figure shows the typical functional areas and flows within warehouses. The main warehouse activities include: receiving, transfer and put away, order picking/selection, accumulation/sortation, cross-docking, and shipping.

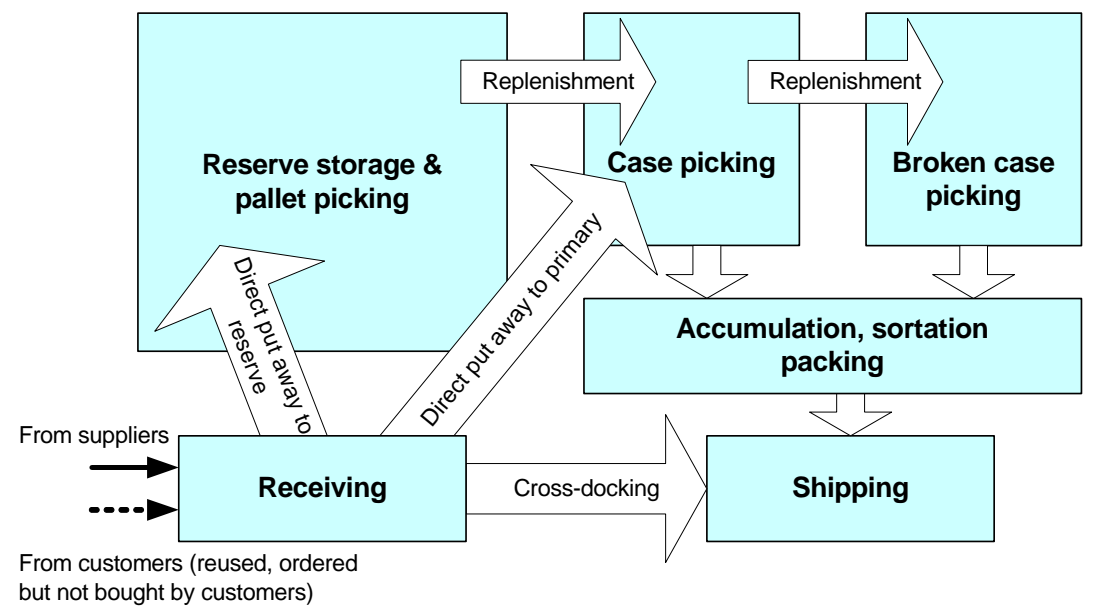

Figure 1 Typical warehouse functions and flows (Tompkins et al. 2003)

The receiving activity includes the unloading of products from the transport carrier, updating the inventory record, inspection to find if there is any quantity or quality inconsistency. Transfer and put away involves the transfer of incoming products to storage locations. It may also include repackaging (e.g. full pallets to cases, or standardised bins), and physical movements (from the receiving docks to different functional areas, between these areas, from these areas to the shipping docks). The order picking/selection is the major activity in most warehouses. It involves the process of obtaining a right amount of the right products for a set of customer orders. The accumulation/sortation of picked orders into individual (customer) orders is a necessary activity if the orders have been picked in batches. In such a case the picked units have to be grouped by customer order, upon completion of the pick process. After picking, orders often have to be packed and stacked on the right unit load (e.g. a pallet). Cross-docking is performed when the received products are transferred directly to the shipping docks (short stays or services may be required but little or no order picking is needed). 


\section{Order picking}

Order picking involves the process of clustering and scheduling the customer orders, assigning stock on locations to order lines, releasing orders to the floor, picking the articles from storage locations and the disposal of the picked articles. Customer orders consist of order lines, each line for a unique product or stock keeping unit (SKU), in a certain quantity. In Figure 1, order lines are split, based on quantity and product carrier of the SKU, in pallet picks, case picks and broken case (unit) picks. Many different order- picking system types can be found in warehouses. Often multiple order-picking systems are employed within one warehouse, for example in each of the three zones of Figure 1. Figure 1 distinguishes order-picking systems according to whether humans or automated machines are used. The majority of warehouses employ humans for order picking. Among these, the picker-to-parts systems, where the order picker walks or drives along the aisles to pick items, are most common (De Koster 2004). We can distinguish two types of picker-to-parts systems: low-level picking and high-level picking. In low-level order-picking systems, the order picker picks requested items from storage racks or bins (bin-shelving storage), while travelling along the storage aisles. Other order-picking systems employ high storage racks; order pickers travel to the pick locations on board of a lifting order-pick truck or crane. The crane automatically stops in front of the appropriate pick location and waits for the order picker to perform the pick. This type of system is called a high-level or a man-aboard order-picking system.

Parts-to-picker systems include automated storage and retrieval systems (AS/RS), using mostly aisle-bound cranes that retrieve one or more unit loads (pallets or bins; in the latter case the system is often called a miniload) and bring them to a pick position (i.e. a depot). At this position the order picker takes the required number of pieces, after which the remaining load is stored again. This type of system is also called a unit-load or end-of-aisle order-picking system. The automated crane (also: storage and retrieval (S/R) machine) can work under different operating modes: single, dual and multiple command cycles. The single-command cycle means that either a load is moved from the depot to a rack location or from a rack location to the depot. In the dual-command mode, first a load is moved from the depot to the rack location and next another load is retrieved from the rack. In multiple command cycles, the S/R machines have more than one shuttle and can pick up and drop off several loads in one cycle. For example, in a four-command cycle (described in Sarker and Babu 1995), the S/R machine leaves the depot with two storage loads, stores them and returns with two retrieved loads. Other systems use modular vertical lift modules (VLM), or carousels that also offer unit loads to the order picker, who is responsible for taking the right quantity.

Put systems, or order distribution systems (see Figure 2) consist of a retrieval and distribution process. First, items have to be retrieved, which can be done in a parts-to-picker or picker-to-parts manner. Second, the carrier (usually a bin) with these pre-picked units is offered to an order picker who distributes them over customer orders ('puts' them in customer cartons). Put systems are particularly popular in case a large number of customer order lines have to be picked in a short time window (for example at the Amazon Germany warehouse, or flower auctions) and can result in about 500 picks on average per order picker hour (for small items) in well-managed systems (De Koster 2004). Newly developed systems indicate that up to 1000 put handlings per picker hour are feasible.

Figure 2 also shows several organisational variants of picker-to-parts systems. The basic variants include picking by article (batch picking) or pick by order (discrete picking). In the case of picking by article, multiple customer orders (the batch) are picked simultaneously by an order picker. Many in-between variants exist, such as picking multiple orders followed by immediate sorting (on the pick cart) by the order picker (sortwhile-pick), or the sorting takes place after the pick process has finished (pick-and-sort). Another basic variant is zoning, which means that a logical storage area (this might be a pallet storage area, but also the entire warehouse) is split in multiple parts, each with different order pickers. Depending on the picking strategy, 
zoning may be further classified into two types: progressive zoning and synchronised zoning. The term wave picking is used if orders for a common destination (for example, departure at a fixed time with a certain carrier) are released simultaneously for picking in multiple warehouse areas. Usually (but not necessarily) it is combined with batch picking. The batch size is determined based on the required time to pick the whole batch completely, often between 30 minutes to 2 hours (see Petersen 2000). Order pickers pick continuously the requested items in their zones, and a next picking wave can only start when the previous one is completed.

Automated and robotised picking is only used in special cases (e.g. valuable, small and delicate items).

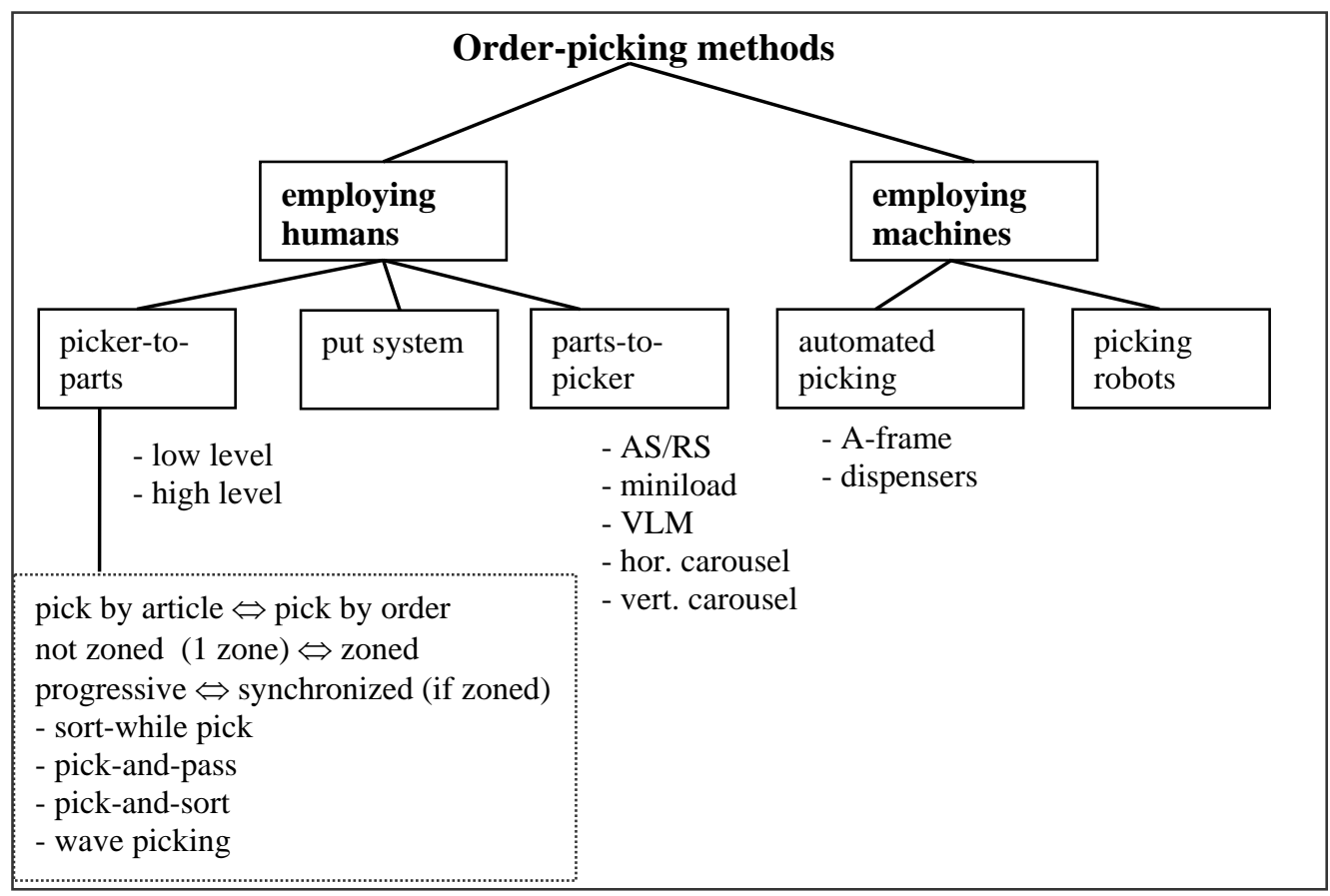

Figure 1 Classification of order-picking systems (based on De Koster 2004)

In this paper we concentrate on low-level, picker-to-parts order-picking systems employing humans (and with multiple picks per route). These systems form the very large majority of picking systems in warehouses worldwide (based on the authors' experience: over $80 \%$ of all order-picking systems in Western Europe). Surprisingly, academic order-picking literature focuses more on high-level picking and AS/RS systems. Although not the main topic of this paper, we will briefly mention some of the latter type of literature as well.

The design of real order-picking systems is often complicated, due to a wide spectrum of external and internal factors which impact design choices. According to Goetschalckx and Ashayeri (1989) external factors that influence the order-picking choices include marketing channels, customer demand pattern, supplier replenishment pattern and inventory levels, the overall demand for a product, and the state of the economy. Internal factors include system characteristics, organisation, and operational policies of order-picking systems. System characteristics consist of mechanisation level, information availability and warehouse dimensionality (see Figure 2). Decision problems related to these factors are often concerned at the design stage. The organisation and operational policies include mainly five factors: routing, storage, batching, zoning and order release mode. Figure 2 also shows the level of complexity of order-picking systems, measured by the distance of the representation of this problem in the axis system to the origin. In other words, the farther a system is located from the origin, the harder the system is to design and control. 

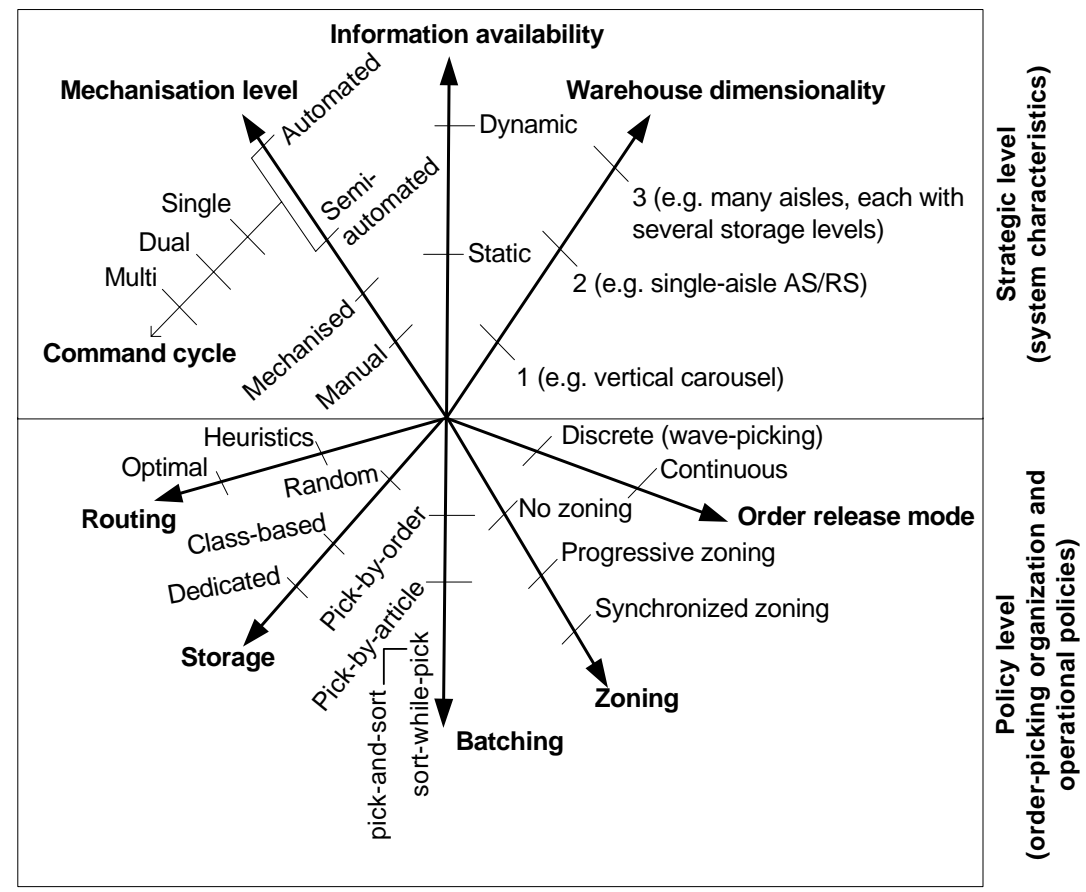

Figure 2 Complexity of order-picking systems (based on Goetschalckx and Ashayeri 1989)

\section{Order picking objectives}

The most common objective of order-picking systems is to maximise the service level subject to resource constraints such as labour, machines, and capital (Goetschalckx and Ashayeri 1989). The service level is composed of a variety of factors such as average and variation of order delivery time, order integrity, and accuracy. A crucial link between order picking and service level is that the faster an order can be retrieved, the sooner it is available for shipping to the customer. If an order misses its shipping due time, it may have to wait until the next shipping period. Also, short order retrieval times imply high flexibility in handling late changes in orders. Minimising the order retrieval time (or picking time) is, therefore, a need for any order-picking system.

Figure 4 shows the order-picking time components in a typical picker-to-parts warehouse. Although various case studies have shown that also activities other than travel may substantially contribute to order-picking time (Dekker et al. 2004, De Koster et al. 1999a), travel is often the dominant component. According to Bartholdi and Hackman (2005) 'travel time is waste. It costs labour hours but does not add value'. It is, therefore, a first candidate for improvement. 


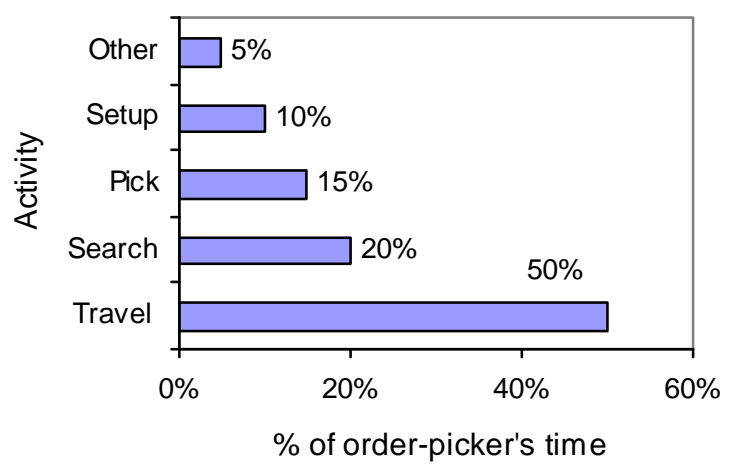

Figure 3 Typical distribution of an order picker’s time (Tompkins et al. 2003)

For manual-pick order-picking systems, the travel time is an increasing function of the travel distance (see, for example, Jarvis and McDowell 1991, Hall 1993, Petersen 1999, Roodbergen and De Koster 2001a,b, Petersen and Aase 2004). Consequently, the travel distance is often considered as a primary objective in warehouse design and optimisation. Two types of travel distance are widely used in the order-picking literature: the average travel distance of a picking tour (or average tour length) and the total travel distance. For a given pick load (a set of orders), however, minimising the average tour length is equivalent to minimising the total travel distance.

Clearly, minimising the average travel distance (or, equivalently, total travel distance) is only one of many possibilities. Another important objective would be minimising the total cost (that may include both investment and operational costs). Other objectives which are often taken into consideration in warehouse design and optimisation are:

- minimising the throughput time of an order

- minimising the overall throughput time (e.g. to complete a batch of orders)

- maximise the use of space

- maximise the use of equipment

- maximise the use of labour

- maximise the accessibility to all items

Companies make decisions on design and control of order picking systems at tactical or operational level, with a different time horizon (Rouwenhorst et al. 2000). Common decisions at these levels are:

- layout design and dimensioning of the storage system (tactical level)

- assigning products to storage locations (storage assignment) (tactical and operational level)

- assigning orders to pick batches and grouping aisles into work zones (batching and zoning) (tactical and operational level)

- order picker routing (routing) (operational level)

- sorting picked units per order and grouping all picks of the orders (order accumulation/sorting) (operational level)

In realising the above objectives, decisions made at the various levels are strongly interdependent. For example, a certain layout or storage assignment may perform well for certain routing strategies, but poorly for others. However, including all decisions (with obvious different decision horizons) in one model is 
intractable. Researchers, therefore, limit themselves to one or few decision areas simultaneously. In practice, decisions are also made sequentially, or variations are simply not considered. In the following sections we therefore subsequently treat these decision areas and mention area interactions observed by authors when appropriate. We first give an introduction to the problem and then briefly mention the concerned literature. Issues in design and planning of warehousing systems have been discussed in Ashayeri and Gelders (1985), Cormier and Gunn (1992), Cormier (1997), Van den Berg (1999), Van den Berg and Zijm (1999) and Rouwenhorst et al. (2000). Issues in design and control of order-picking processes in particularly are mentioned in Goetschalckx and Ashayeri (1989), Choe and Sharp (1991), Roodbergen (2001) and Wäscher (2004). An extensive bibliography on order-picking systems is gathered in Goetschalckx and Wei (1994) and Roodbergen (2001). As many papers on the order-picking problem have appeared recently, most of the abovementioned overview publications are not up-to-date. Wäscher (2004) chooses a similar approach to ours and discusses storage assignment, order batching and picker routing problems, but treats only a small fraction of the available literature.

\section{Layout design}

In the context of order picking, the layout design concerns two sub-problems: the layout of the facility containing the order-picking system and the layout within the order-picking system. The first problem is usually called the facility layout problem; it concerns the decision of where to locate various departments (receiving, picking, storage, sorting, and shipping, etc.). It is often carried out by taking into account the activity relationship between the departments. The common objective is minimising the handling cost, which in many cases is represented by a linear function of the travel distance. We refer to Tompkins et al. (2003) for a description of several efficient layout design procedures and to Meller and Gau (1996) for a general literature overview on this subject. Furthermore, Heragu et al. (2005) give a model and heuristic for sizing of areas and assignment of products to areas. In this paper, we focus on the second sub-problem, which can also be called the internal layout design or aisle configuration problem. It concerns the determination of the number of blocks, and the number, length and width of aisles in each block of a picking area (see Figure 5). The common goal is to find a 'best' warehouse layout with respect to a certain objective function among the layouts which fit a given set of constraints and requirements. Again, the most common objective function is the travel distance.

Literature on layout design for low-level manual order-picking systems is not abundant. An early publication, albeit focussing on unit loads, is by Bassan et al. (1980). They compare two different parallel-aisle layouts for handling (including travel) and layout costs. Rosenblatt and Roll (1984), using both analytical and simulation methods, study the effect of storage policy (i.e. how to assign products to storage locations) on the internal layout of warehouse. Rosenblatt and Roll (1988) examine the effect of stochastic demands and different service levels on the warehouse layout and storage capacity. Recently, Roodbergen (2001) proposed a nonlinear objective function (i.e. average travel time in terms of number of picks per route and pick aisles) for determining the aisle configuration for random storage warehouses (including single and multiple blocks) that minimises the average tour length. Also considering minimisation of the average tour length as the major objective, Caron et al. (2000) consider 2-block warehouses (i.e., one middle cross aisle) under the COI-based storage assignment (see Section 4 for a discussion of storage assignment methods), while Le-Duc and De Koster (2005b) focus on the class-based storage assignment. For both random and volume-based storage assignment methods, Petersen (2002) shows, by using simulation, the effect of the aisle length and number of aisles on the total travel time. Much of the existing knowledge on warehouse layout is captured in the Erasmus-Logistica website (http://www.fbk.eur.nl/OZ/LOGISTICA) that can be used to interactively optimise warehouse layouts for various storage and routing strategies. 


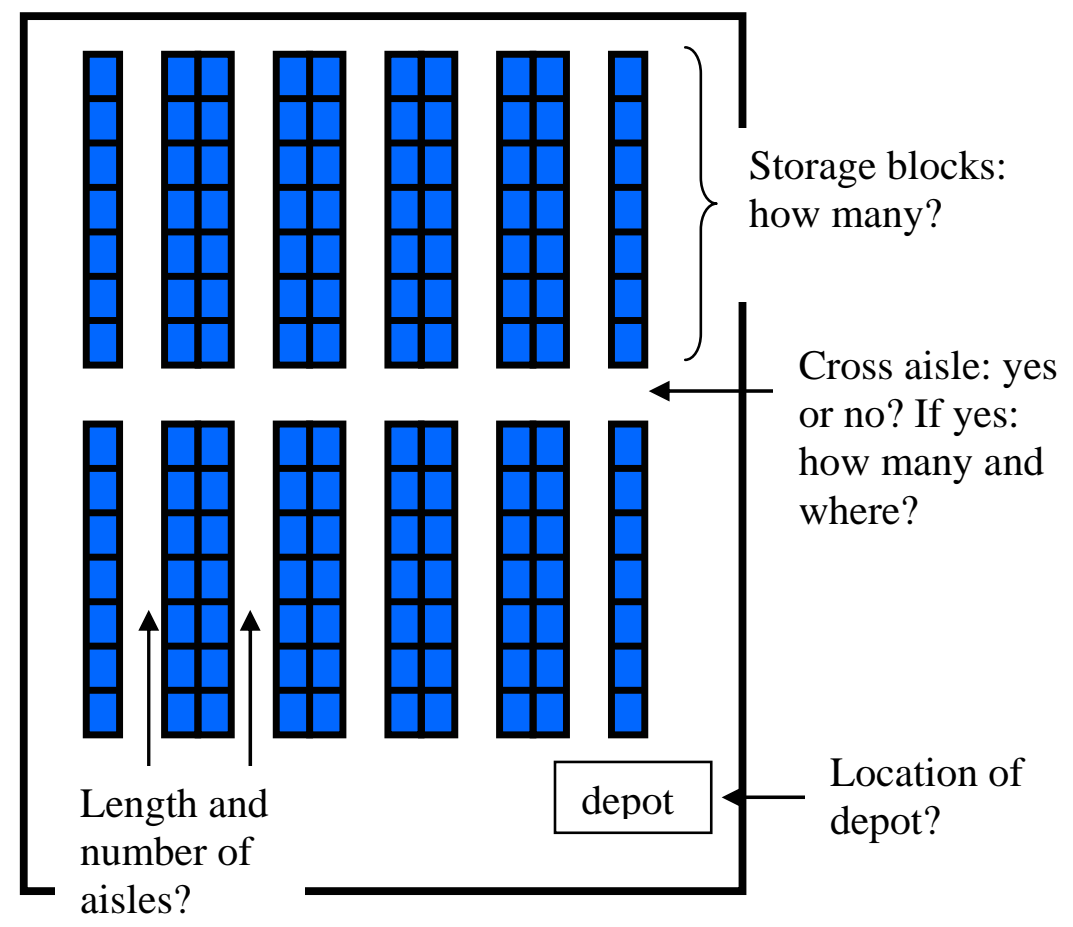

Figure 4 Typical layout decisions in order picking system design (top view of storage area)

Compared to manual-pick order-picking systems, the layout design problem for unit-load (mainly AS/RS) systems has received much attention. For a literature review on throughput time models for AS/RS, we refer to Sarker and Babu (1995), Johnson and Brandeau (1996), Van den Berg (1999), and Le-Duc (2005). We briefly mention here the literature focussing on designing the picking face. For random storage assignment, Bozer and White (1984) show that a square-in-time rack (i.e. a rack where the ratio of height to length equals the ratio of the S/R machine vertical to horizontal velocity) is optimal for single and dual-command cycles. Larson et al. (1997) use a heuristic approach to layout a unit-load warehouse and to assign product classes to locations, with the objective of increasing floor space utilisation and decreasing travel distance. Eldemir et al. (2004) give estimates for storage requirements. Few papers deal with layouting three-dimensional unit-load systems. Park and Webster (1989) are an exception. They deal with the problem of finding rack locations for product turnover classes to minimise the travel time. De Koster and Le-Duc (2005) extend Bozer and White's (1984) method to determine the optimal dimensions of a three-dimensional rack of given capacity that minimise the unit-load retrieval time.

\section{Storage assignment}

Products need to be put into storage locations before they can be picked to fulfil customer orders. A storage assignment method is a set of rules which can be used to assign products to storage locations. Before such an assignment can be made, however, a decision must be made which pick activities will take place in which storage system. 


\section{Forward - reserve allocation}

In order to speed up the pick process, it is in many cases efficient to separate the bulk stock (reserve area) from the pick stock (forward area). The size of the forward area is restricted: the smaller the area, the lower the average travel times of the order pickers will be. It is important to decide how much of each SKU is placed in the forward area and where in the area it has to be located. Figure 2 shows three areas in which a single SKU can be stored and picked, depending on the storage and pick quantity. Dividing a SKU's inventory over multiple areas implies regular internal replenishments from the reserve to the forward area. One of the trade-offs to be made is then to balance additional replenishment efforts over extra pick effort savings. It may even be advantageous to store some of the SKUs only in the reserve area, for example if demand quantities are high or if demand frequencies are low. Furthermore, replenishments are often restricted to times at which there is no order picking activity, which gives additional constraints. The decisions concerning the problems described here are commonly called the forward-reserve problem. Literature includes Frazelle et al. (1994) Hackman and Platzman (1990), and Van den Berg et al. (1998). In their book Warehouse science, Bartholdi and Hackman (2005) devote a full chapter to this problem.

A concept closely related to the forward-reserve problem is dynamic storage. It aims at making the pick area very small in order to reduce travel time, and bringing the SKUs to the storage locations dynamically, just in time for the pick (by an automated crane, carousel, or VLM). The number of locations available in the forward area is usually smaller than the total number of SKUs. As these systems are capable of achieving very high picker productivity, they are becoming more and more popular (according to the authors' knowledge at least 15 implementations the last few years in Western Europe). The interesting decision problems are in the interaction of the grouping of orders in a batch (more orders means less replenishments, but simultaneously more SKUs are needed implying larger travel distances), the assignment of SKUs to locations, the timing of the replenishments, and scheduling of the automated crane. This area is still virgin ground for academics.

\section{Storage assignment policies}

There are numerous ways to assign products to storage locations within the forward and reserve storage areas. We describe five frequently used types of storage assignment: random storage, closest open location storage, dedicated storage, full turnover storage and class based storage. For random storage every incoming pallet (or an amount of similar products) is assigned a location in the warehouse that is selected randomly from all eligible empty locations with equal probability (see e.g. Petersen, 1997). The random assignment method results in a high space utilisation (or low space requirement) at the expense of increased travel distance (Choe and Sharp, 1991). The random storage policy will only work in a computer-controlled environment. If the order pickers can choose the location for storage themselves we would probably get a system known as closest open location storage. The first empty location that is encountered by the employee will be used to store the products. This typically leads to a warehouse where racks are full around the depot and gradually more empty towards the back (if there is excess capacity). Hausman et al. (1976) argue that closest open location storage and random storage have a similar performance if products are moved by full pallets only.

Another possibility is to store each product at a fixed location, which is called dedicated storage. A disadvantage of dedicated storage is that a location is reserved even for products that are out of stock. Moreover, for every product sufficient space has to be reserved such that the maximum inventory level can be stored. Thus the space utilisation is lowest among all storage policies. An advantage is that order pickers become familiar with product locations. In retail warehouses often the product-to-location assignment matches the layout of the stores (De Koster and Neuteboom, 2001). This can save work in the stores because the products are logically grouped. Finally, dedicated storage can be helpful if products have different 
weights. Heavy products have to be on the bottom of the pallet and light products on top. By storing products in order of weight and routing the order pickers accordingly, a good stacking sequence is obtained without additional effort. Dedicated storage can be applied in pick areas, with a bulk area for replenishment that may have, for example, random storage. In this way, the advantages of dedicated storage still hold, but the disadvantages are only minor because dedicated storage is applied only to a small area.

A fourth storage policy is full-turnover storage. This policy distributes products over the storage area according to their turnover. The products with the highest sales rates are located at the easiest accessible locations, usually near the depot. Slow moving products are located somewhere towards the back of the warehouse. An early storage policy of this type is the cube-per-order index (COI) rule, see Heskett (1963, 1964). The COI of an item is defined as the ratio of the item's total required space to the number of trips required to satisfy its demand per period. The algorithm consists of locating the items with the lowest COI closest to the depot. See also Kallina and Lynn (1976), Malmborg and Bhaskaran (1987, 1989, 1990) and Malmborg (1995, 1996). A practical implementation of full-turnover policies would be easiest if combined with dedicated storage. The main disadvantage is that demand rates vary constantly and the product assortment changes frequently. Each change would require a new ordering of products in the warehouse resulting in a large amount of reshuffling of stock. A solution might be to carry out the restocking once per period. The loss of flexibility and consequently the loss of efficiency might be substantial when using fullturnover storage. The adoption of COI-based storage assignment, or other assignments based on demand frequency generally require a more 'information intensive' approach than random storage, since order and storage data must be processed in order to rank and assign products (Caron et al. 1998). In some cases this information may not be available, for example, because the product assortment changes too fast to build reliable statistics (see De Koster et al., 1999a).

\section{Class-based storage}

The concept of class-based storage combines some of the methods mentioned so far. In inventory control, a classical way for dividing items into classes based on popularity is Pareto's method. The idea is to group products into classes in such a way that the fastest moving class contains only about $15 \%$ of the products stored but contributes to about $85 \%$ of the turnover ${ }^{2}$. Each class is then assigned to a dedicated area of the warehouse. Storage within an area is random. Classes are determined by some measure of demand frequency of the products, such as COI or pick volume. Fast moving items are generally called A-items. The next fastest moving category of products is called B-items, and so on. Often the number of classes is restricted to three, although in some cases more classes can give additional gains with respect to travel times.

Based on simulation experimental results, Petersen et al. (2004) show that with regards to the travel distance in a manual order-picking system, full-turnover storage outperforms class-based storage. The gap between the two depends on the class partition strategy (i.e. number of classes, percentage of the total volume per class) and the routing method used. However, they suggest using the class-based method with 2 to 4 classes in practice as it is easier to implement than the volume-based method; it does not require a complete list of the items ranked by volume and it requires less time to administer than the other dedicated methods do. While for AS/RS, Yang (1988) and Van den Berg and Gademann (2000) found that (in their studies) 6-class is the best among other options. The advantage of this way of storing is that fast-moving products can be stored close to the depot and simultaneously the flexibility and low storage space requirements of random storage are applicable. Graves et al. (1977) observe that in order to enable an incoming load to be stored in the correct

\footnotetext{
2 It is based on an observation of the Italian sociologist and economist Vilfredo Pareto: "85\% of the wealth of the world is held by $15 \%$ of the people".
} 
class region, empty slots must be available, thus increasing space requirements with the number of classes. Accordingly, class-based storage requires more rack space than randomised storage.

Most research on class-based storage has been performed in the context of AS/RS. Hausman et al. (1976) consider the problem of finding class regions for an AS/RS using the class-based storage assignment method and the single-command operating mode. The authors prove that L-shaped class regions where the boundaries of zones accommodating the corresponding classes are square-in-time are optimal with respect to minimising the mean single-command travel time. They also analytically determine optimal storage class-sizes for two product classes. Rosenblatt and Eynan (1989) extend these results and establish optimal class boundaries for any given number of classes in a square-in-time rack. Eynan and Rosenblatt (1994) extend this method further to any rectangular rack. For S/R machines with dual-command cycles and class-based storage racks, Graves et al. (1977) show by simulation that the L-shaped regions with square-in-time boundaries are not necessarily optimal. However, an L-shaped class allocation will in general be no more than 3\% above the optimum. For multi-command cycles with class-based storage, Guenov and Raeside (1992) compare three zone shapes. Ashayeri et al. (2003) develop a travel time calculation method used for designing storage-class shapes in both square-in-time and non-square-in-time racks with single and multiple depots.

Various possibilities exist for positioning the A-, B- and C-areas in low-level picker-to-part systems. Jarvis and McDowell (1991) suggest that each aisle should contain only one class, resulting in the within-aisle storage as depicted in Figure 6. Petersen (1999, 2002), Petersen and Schmenner (1999), Petersen and Aase (2004) and Petersen et al. (2004) compare multiple configurations among which across-aisles storage (also depicted in Figure 6). Roodbergen (2005) compares various storage assignment policies for warehouse layouts with multiple cross aisles. Based on a closed form travel-time estimate for the return routing policy, Le-Duc and De Koster (2005c) optimise the storage-class positioning. They claim that the across-aisle storage method is close to optimal. Le-Duc (2005) extends these results for other routing policies. The optimal storage strategy depends on the routing policies (and on warehouse size and number of SKUs per pick route). In the warehousing literature, there is no firm rule to define a class partition (number of classes, percentage of items per class, and percentage of the total pick volume per class) for low-level picker-to-part systems.

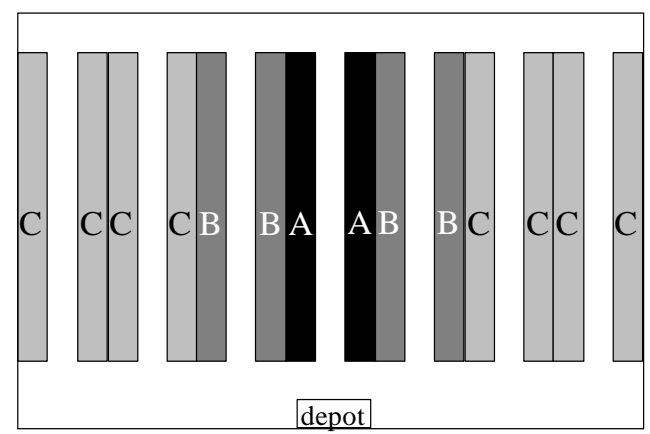

within-aisle storage

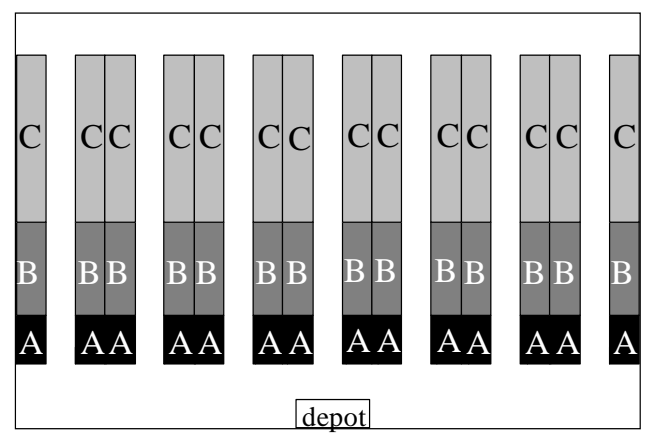

across-aisle storage

Figure 6 Illustration of two common ways to implement class-based storage.

\section{Family grouping}

All storage assignment policies discussed so far have not entailed possible relations between products. For example, customers may tend to order a certain product together with another product. In this case, it may be interesting to locate these two products close to each other. An example of this is called family-grouping, where similar products are located in the same region of the storage area. Clearly, grouping of products can be 
combined with some of the previously mentioned storage policies. For example, it is possible to use classbased storage and simultaneously group related items. However, the decision in which class to locate the products has to depend on a combination of the properties of all products in the group. Roll and Rosenblatt (1983) compare the space requirements for the random and grouped storage for a port warehouse and show that the grouped storage assignment increases space requirements compared to random storage assignment. Rosenblatt and Roll (1984) set up a model for warehousing costs, taking the effect of space requirements into account.

To apply family grouping, the statistical correlation between items (e.g. frequency at which they appear together in an order, see Frazelle and Sharp 1989 and Brynzer and Johansson 1996) should be known or at least be predictable. In the literature, two types of family grouping are mentioned. The first method is called the complimentary-based method, which contains two major phases. In the first phase, it clusters the items into groups based on a measure of strength of joint demand ('complimentary'). In the second phase, it locates the items within one cluster as close to each other as possible (Wäscher 2004). Rosenwein (1994) shows that the clustering problem can be formulated as a p-median problem. For finding the position of clusters, Liu (1999) suggests that the item type with the largest demand should be assigned to the location closest to the depot (volume-based strategy), while Lee (1992) proposes to take into account also the space requirement (COI-based strategy). The second type of family-grouping method is called the contact-based method. This method is similar to the complimentary method, except it uses contact frequencies to cluster items into groups. For a given (optimal) routing solution, a contact frequency between item type $i$ and item type $j$ is defined as the number of times that an order picker picks either item type $i$ directly after item type $j$, or item type $j$ directly after item type $i$. However, the routing decision is dependent on the location of the item types, which demonstrates the strong interrelationship between item location and routing. Due to the fact that finding a joint optimal solution for both problems is not a realistic approach, at least not for problem instances of the size encountered in practice, contact-based solution methods alternate between the two problem types (Wäscher 2004). The contact-based method is considered, for example, in Van Oudheusden et al. (1988) and Van Oudheusden and Zhu (1992).

\section{Zoning}

As an alternative to single order picking, the order picking area can be divided into zones. Each order picker is assigned to pick the part of the order that is in his assigned zone. Compared to other planning issues, the zoning problem has received little attention despite its important impact on the performance of order-picking systems. Possible advantages of zoning include the fact that each order picker only needs to traverse a smaller area, reduced traffic congestion, and furthermore the possibility that order pickers become familiar with the item locations in the zone. The main disadvantage of zoning is that orders are split and must be consolidated again before shipment to the customer. Two approaches can be used to cope with this. The first approach is that of progressive assembly of an order. Using this approach one order picker starts on the order. When he finishes his part, the tote and pick list (or any other means that are used) are handed to the next picker, who continues the assembly of the order. Hence an order (or batch of orders) is only finished after having visited all relevant zones. This system is also called pick-and-pass. The second approach for zoning is parallel (or synchronised) picking, where a number of order pickers start on the same order, each order picker in his own zone. The partial orders are merged after picking. In practice, zoning is partially based on product properties, like size, weight, required temperature and safety requirements.

Little literature on zoning is available. A generic discussion on zoning is given in Speaker (1975). De Koster (1994) models a zoned pick-and-pass system as a Jackson queuing network which allows rapid estimation of 
order throughput times and average work-in-process. Results are compared with simulations. The estimates can be used to determine the number of zones and the system size. Mellema and Smith (1988) examine the effects of the aisle configuration, stocking policy and batching and zoning rules by using simulation. They suggest that a combination of batching and zoning can significantly increase the productivity (pieces per manhour). Also, using simulation, Petersen (2002) shows that the zone shape (number of aisles per zone, the aisle lengths), the number of items on the pick-list and the storage policy have a significant effect on the average travel distance within the zone. Choe et al. (1993) study the effects of three strategies in an aisle-based orderpicking system: single-order-pick, sort-while-pick, and pick-and-sort. They propose analytical tools for a planner to quickly evaluate various alternatives without using simulation. In Malmborg (1995) the problem of assigning products to locations is studied with zoning constraints. Brynzer and Johansson (1995) describe a case study with zoning and batching. An important issue, particularly in progressive zoning is that the workload must be equally distributed (balanced) over the order pickers. Analogous to manufacturing flow lines, imbalance can cause serious deterioration of order throughput and order throughput time. Jane (2000) proposes several heuristic algorithms to balance the workloads among the order picker and to adjust the zone size for order volume fluctuation in a progressive zoning system. Jane and Laih (2005) consider the problem of heuristically assigning products to zones in a synchronised system. The method is based on co-appearance of items in the same order (i.e. items appear in the same order are stored in the same zone). Jewkes et al. (2004) tackle the product assignment problem (as well as zone sizing and picker home base location) for a progressive system. Their method is based on dynamic programming. Using a mixed-integer linear program, Le-Duc and De Koster (2005a) determine the optimal number of zones in a synchronised zoning system such that the total order-picking and assembly time is minimised.

An alternative for progressive zoning with fixed zone sizes, would be a more dynamic way of zone sizing and assigning order pickers to zones. The bucket-brigades concept is an example of this. It coordinates workers who are progressively assembling products along a flow line. The idea is roughly as follows. There is one rack from which the products are to be retrieved. One order picker starts an order at the far left of the rack. He picks a number of products and at some point gives the partially fulfilled order to the next order picker, who continues picking the products along the line. The order is handed from picker to picker until it reaches the far right of the line, where it is put on a conveyor for further transport. The special feature of the bucket brigades is the way in which it is determined when an order is handed from one order picker to the next. Suppose, at some point in time all order pickers are working on separate orders, if the order picker closest to the end of the line deposits his finished order, he walks back along the line towards the starting point. If he meets another order picker, he then takes over the order from the other person and continues picking this order. The order picker from which the order was taken moves back along the line until he meets another order picker, and so on. One order picker starts all orders. The order pickers have to be in sequence of their respective speed of working for the system to function adequately. The main advantage of bucket brigades is that they are selfbalancing with respect to workload. See Bartholdi (1993), Bartholdi et al. $(1999,2005)$ and Bartholdi and Eisenstein (1996, 2005a,b). Bartholdi et al. (2001) report the implementation of bucket brigades in a distribution centre and show that bucket brigades increased the throughput rate and reduced management efforts.

\section{Batching}

When orders are fairly large, each order can be picked individually (i.e. one order per picking tour). This way of picking is often referred as the single order picking policy (or discrete or pick-by-order). However, when orders are small, there is a potential for reducing travel times by picking a set of orders in a single picking tour. Order batching is the method of grouping a set of orders into a number of sub-sets, each of which can 
then be retrieved by a single picking tour. According to Choe and Sharp (1991), there are basically two criteria for batching: the proximity of pick locations and time window batching.

Proximity batching assigns each order to a batch based on proximity of its storage location to those of other orders. The major issue in proximity batching is how to measure the proximities among orders, which implicitly assumes a pick sequencing rule to visit a set of locations. Gademann et al. (2001) consider the proximity order-batching problem in a manual-pick wave-picking warehouse. The objective is to minimise the maximum lead-time of any batch (this is known as a common objective in wave picking). They show that the order-batching in this case is an NP-hard problem. They propose a branch-and-bound algorithm to solve this problem exactly for small instances and a 2-opt heuristic procedure for large instances. Furthermore, they claim that the 2-opt heuristic provides very tight upper bounds and would suffice in practice. Also for a manual picking system, Gademann and Van de Velde (2005) consider the order-batching problem with a more general objective: minimising the total travel time. They show that the problem is still NP-hard in the strong sense when the number of orders per batch is greater than 2. A branch-and-price algorithm is designed to solve instances of modest size to optimality. For larger instances, it is suggested to use an iterated descent approximation algorithm. Chen and $\mathrm{Wu}$ (2005) measure the proximity of orders by taking into account the level of "association" between orders (orders having more similar items have a high association and may form a batch). They develop a clustering model based on 0-1 integer programming to maximise the total association of batches. A data-mining approach is given in Chen et al. (2005) and genetic algorithms are employed in Hsu et al. (2005).

As order batching is an NP-hard problem, many studies focus on developing heuristic methods for solving it. For manual picking systems, we can distinguish two types of order-batching heuristics: seed and savings algorithms. Seed algorithms construct batches in two phases: seed selection and order congruency. Seed selection rules define a seed order for each batch. Some examples of a seed selection rule are: (a) a random order; (b) an order with large number of positions; (c) an order with longest pick tour; (d) an order with most distantly-located (i.e. furthest from the depot); (f) an order with the largest difference between the aisle number of the right-most and the left-most aisle to be visited (see De Koster et al. 1999b for more seed selection rules). Order congruency rules determine which unassigned order should be added next into the current batch. Usually, an order is selected, to be included in a batch, based on a measure of the 'distance' from the order to the seed order of the batch. Examples are: (a) the number of additional aisles which have to be visited if the order is added; (b) the different between the gravity centre of the order and the gravity centre of the seed order; (c) the sum of the travel distances between every location of an item in the order and the closest location of item in the seed order. Seed algorithms are considered in Elsayed (1981), Elsayed and Stern (1983), Hwang et al. (1988), Hwang and Lee (1988), and Pan and Liu (1995) for single aisle man-onboard AS/RS systems, and in Gibson and Sharp (1992), Rosenwein (1994), Ruben and Jacobs (1999) and De Koster et al. (1999b) for multiple aisle systems. Saving algorithms are based on the algorithm of Clarke and Wright (1964) for the vehicle routing problem: a saving on travel distance is obtained by combining a set of small tours into a smaller set of larger tours. Elsayed and Unal (1989) propose four batching heuristics of which the SL algorithm (combine Small with Large orders), which classifies orders as 'large' or 'small' ones before assigning them to different batches, generates smallest travel distances.

De Koster et al. (1999b) perform a comparative study for the seed and time savings heuristics mentioned above for multiple-aisle picker-to-parts systems. The performance of the algorithms is evaluated using two different routing heuristics. The batching heuristics are compared for travel time, number of batches formed and also for the applicability in practice. They conclude that: (a) even simple order batching methods lead to significant improvement compared to the first-come first-serve batching rule; (b) the seed algorithms are best 
in conjunction with the S-shape routing method and a large capacity of the pick device, while the time savings algorithms perform best in conjunction with the largest gap routing method and a small pick-device capacity.

Under time window batching, the orders arriving during the same time interval (fixed or variable length), called a time window, are grouped as a batch. These orders are then processed simultaneously in the following stages. If order splitting is not allowed (thus each order picker picks a group of complete orders in one picking tour), it is possible to sort items by order during the picking process. This picking strategy is often referred as the sort-while-pick picking strategy. If order splitting is possible, a further effort is needed to sort the items after picking (the pick-and-sort strategy). Tang and Chew (1997), Chew and Tang (1999) and Le-Duc and De Koster (2003a, 2003b) consider variable time window order batching (i.e. number of items per batch is 'fixed') with stochastic order arrivals for manual picking systems. They model the problem as a batch service. For each possible picking batch size, they first estimate the first and second moments of the service time. Then using these moments, they can find the time in system of a random order. The optimal picking batch size is then determined in a straightforward manner. Results from the simulation experiments show this approach provides a high accuracy level. Furthermore, it is simple and can be easily applied in practice.

All publications mentioned-above do not take into account the order due time and the penalty of violating the due time. Elsayed et al. (1993) and Elsayed and Lee (1996) consider the order-batching problem in a manaboard system with minimising of the penalties and tardiness as respective objectives. They propose a heuristic which first establishes batches and then determines the release times for the batches. Won and Olafsson (2005) focus on customer response times by jointly considering the batching and picking operation.

\section{Routing methods}

The objective of routing policies is to sequence the items on the pick list to ensure a good route through the warehouse. The problem of routing order pickers in a warehouse is actually a special case of the Travelling Salesman Problem, see also Lawler et al. (1985). The travelling salesman problem owes its name to the problem described by the following situation. A salesman, starting in his home city, has to visit a number of cities exactly once and return home. He knows the distance between each pair of cities and wants to determine the order in which he has to visit the cities such that the total travelled distance is as small as possible. Clearly, the situation of the travelling salesman has many similarities with that of an order picker in a warehouse. The order picker starts at the depot (home city), where he receives a pick list, has to visit all pick locations (cities) and finally has to return to the depot. An example layout of a warehouse with pick and a corresponding graph representation is given in Figure 7.
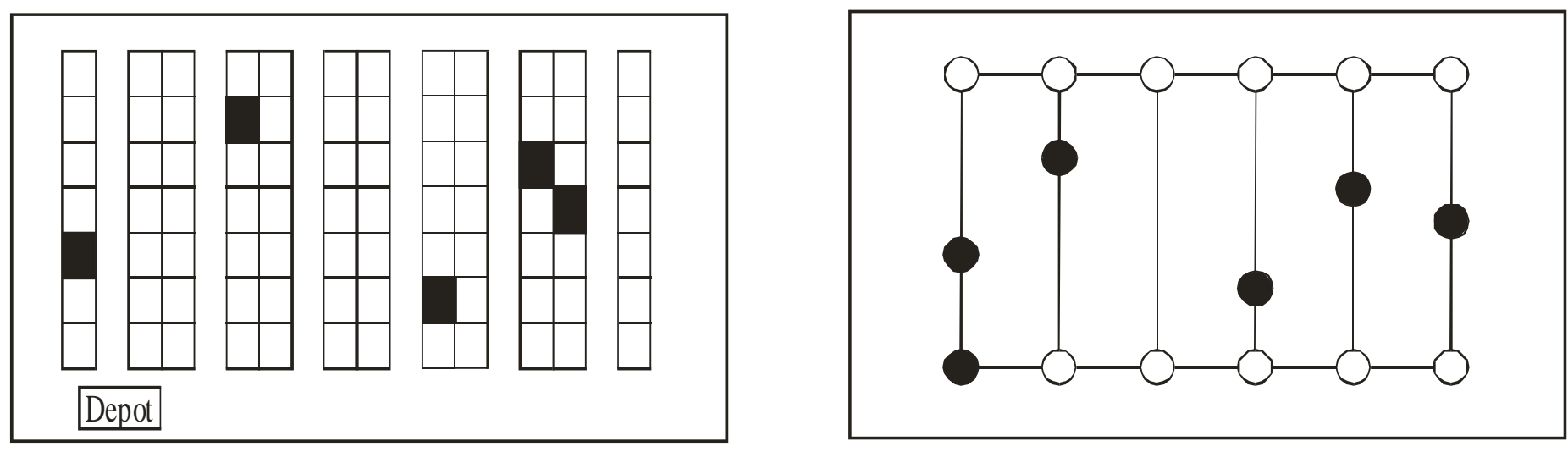

Figure 7 Illustration of an order picking situation (left) and its graph representation (right) 
Some differences exist between the classical Travelling Salesman Problem and the situation of order picking in warehouses. First of all, if we look at the graph in Figure 7, a number of nodes do not have to be visited (indicated with white circles). These nodes are the cross points between aisles and cross aisles. The order picker is allowed to visit them, but does not have to. The black circles represent the pick locations and the depot; these nodes must be visited. It is permissible to visit the pick locations and depot more than once. The problem of order picking classifies as a Steiner Travelling Salesman Problem because of the two facts that some of the nodes do not have to be visited and that the other nodes can be visited more than once. The difficulty with the (Steiner) Travelling Salesman Problem is that it is in general not solvable in polynomial time. However, for type of warehouse shown in Figure 7, it was shown by Ratliff and Rosenthal (1983) that there does exist an algorithm that can solve the problem in running time linear in the number of aisles and the number of pick locations.

In Cornuéjols et al. (1985) it is shown that the algorithm of Ratliff and Rosenthal (1983) can be extended to solve the Steiner Traveling Salesman Problem in all, so-called, series-parallel graphs. In De Koster and Van der Poort (1998) and Roodbergen and De Koster (2001) the algorithm by Ratliff and Rosenthal (1983) is extended to different warehouse situations that cannot be represented as series-parallel graphs. The algorithm from De Koster and Van der Poort (1998) can determine shortest order picking routes in a warehouse of one block with decentralised depositing. Decentralised depositing means that order picker can deposit picked items at the head of every aisle, for example on a conveyor. Instructions for the next route are given via a computer terminal. Roodbergen and De Koster (2001b) developed an algorithm for a warehouse with three cross aisles, one in the front, one in the back, and one in the middle.

\section{Routing heuristics}

In practice, the problem of routing order pickers in a warehouse is mainly solved by using heuristics. This is due to some disadvantages of optimal routing in practice. Firstly, it must be noted that an optimal algorithm is not available for every layout. Secondly, optimal routes may seem illogical to the order pickers who then, as a result, deviate from the specified routes (Gademann and Van de Velde 2005). Thirdly, a standard optimal algorithm cannot take aisle congestion into account, while with heuristic methods it may be possible to avoid (or at least to reduce) the aisle congestion (i.e. the S-shape method has a single traffic direction if the pick density is sufficiently high). Hall (1993), Petersen (1997) and Roodbergen (2001) distinguish several heuristic methods for routing order pickers in single-block warehouses. Example routes are shown in Figure 8.

One of the simplest heuristics for routing order pickers is the S-shape (or traversal) heuristic. Routing order pickers by using the S-shape method means that any aisle containing at least one pick is traversed entirely (except potentially the last visited aisle). Aisles without pick are not entered. From the last visited aisle, the order picker returns to the depot. Another simple heuristic for routing order pickers is the return method, where an order picker enters and leaves each aisle from the same end. Only aisles with picks are visited. The midpoint method essentially divides the warehouse into two areas (see Figure 8). Picks in the font half are accessed from the front cross aisle and picks in the back half are accessed from the back cross aisle. The order picker traverses to the back half by either the last or the first aisle to be visited. According to Hall (1993), this method performs better than the S-shape method when the number of picks per aisle is small (i.e. one pick per aisle on average).

The largest gap strategy is similar to the midpoint strategy except that an order picker enters an aisle as far as the largest gap within an aisle, instead of the midpoint. The gap represents the separation between any two adjacent picks, between the first pick and the front aisle, or between the last pick and the back aisle. If the largest gap is between two adjacent picks, the order picker performs a return route from both ends of the aisle. 
Otherwise, a return route from either the front or back aisle is used. The largest gap within an aisle is therefore the portion of the aisle that the order picker does not traverse. The back aisle can only be accessed through either the first or last aisle. The largest gap method always outperforms the midpoint method (see Hall 1993). However, from an implementation point of view, the midpoint method is simpler. For the combined (or composite) heuristic, aisles with picks are either entirely traversed or entered and left at the same end. However, for each visited aisle, the choice is made by using dynamic programming (see Roodbergen and De Koster 2001a).

Petersen (1997) carried out a number of numerical experiments to compare six routing methods: the S-shape, return, largest gap, mid-point, composite and optimal in a situation with random storage. He concludes that a best heuristic solution is on average 5\% over the optimal solution. A route improvement method using Lin and Kernighan’s (1973) k-opt methodology is presented by Makris and Giakoumakis (2003).

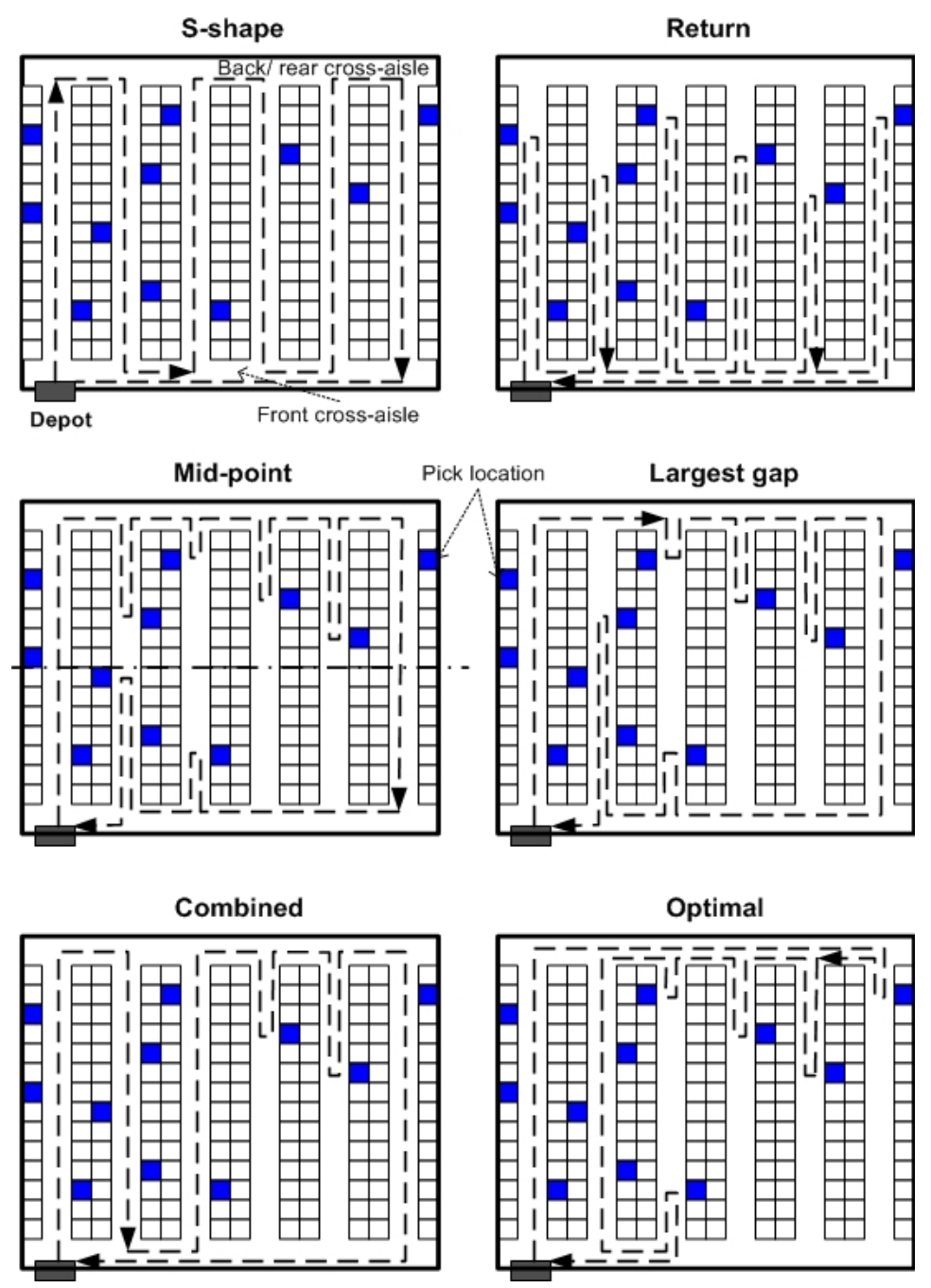

Figure 8 Example of a number of routing methods for a single-block warehouse (Roodbergen, 2001)

All above-mentioned methods were originally developed for single-block warehouses, however, they can be used for multiple-block warehouses with some modifications (see Roodbergen and De Koster, 2001a). 
Methods specifically designed for multiple-block warehouses can be found in Vaughan and Petersen (1999) and Roodbergen and De Koster (2001a). The latter paper compared six routing methods (optimal, largest gap,

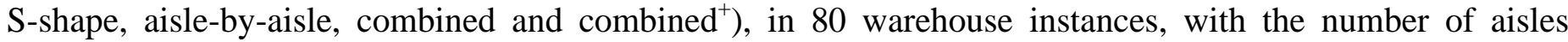
varying between 7 and 15, the number of cross aisle between 2 and 11 and the pick-list size between 10 and 30. They report that the combined ${ }^{+}$heuristic gives the best results in 74 of the 80 instances they analysed.

\section{Other routing issues}

All articles discussed so far assume that the aisles of the warehouse are narrow enough to allow the order picker to retrieve products from both sides of the aisle without changing position. In Goetschalckx and Ratliff (1988b) a polynomial-time optimal algorithm is developed that solves the problem of routing order pickers in wide aisles. Another problem with routing may arise if products are stored at multiple locations in a warehouse. In this case a choice has to be made from which location the products have to be retrieved. A model for the problem of simultaneous assignment of products to locations and routing of order pickers is given in Daniels et al. (1998). Furthermore, heuristics are given to solve the problem. A further routing problem is that of allowing the order picker to do multiple picks per stop. That is, the order picker travels through a warehouse with a vehicle. He stops the vehicle and walks forth and back to a number of pick locations to retrieve products. Then he continues to the next stop location, and so on. The trade-off is between the time to start and stop the vehicle and the distance walked by the order picker. This problem was analysed and solved optimally in Goetschalckx and Ratliff (1988a).

\section{Analytical estimation of routing time}

Part of the research on routing consists of travel time estimation. Using techniques from statistics and operations research an attempt is made to give an estimate of how much time (or distance) it takes to collect an order. Many results are known for systems where the vehicle is confined to a single aisle, see for example Bozer and White (1984). For travel time estimates of single and dual command cycles in multiple aisle systems see e.g. Bassan et al. (1980), Francis (1967), Larson et al. (1997) and Pandit en Palekar (1993). A recent interesting addition is Bozer and Cho (2005) where analytical expressions are presented for an AS/RS under stochastic demand.

Few researchers have looked for travel time estimates for picking in systems with multiple aisles and multiple picks per route. Kunder and Gudehus (1975) give travel time estimations for three routing heuristics in a warehouse consisting of one block. This work is extended in Hall (1993) with more advanced routing heuristics for one block warehouses. Furthermore, a lower bound on travel time for the optimal algorithm from Ratliff and Rosenthal (1983) is given. Formulations for average travel time in a situation with decentralised depositing are given in De Koster et al. (1998). From Hall's analyses it appears that largest gap outperforms S-shape when the pick density is less than about 4 picks per aisles. De Koster and Van der Poort (1998) and De Koster et al. (1998) use simulation to compare the optimal and S-shape methods for several single-block random storage warehouses. They find that the S-shape provides routes which are, on average, between 7\% and 33\% longer than the optimum solutions. Even though no paper has included this notion, it would actually be fairly simple to prove on the basis of statistical properties that for random storage situations an upper bound for the average length of S-shape routes equals two times the average length of optimal routes.

Both Hall (1993) and Kunder and Gudehus (1975) assume that pick locations are distributed randomly over the order picking area according to a uniform distribution. In Jarvis and McDowell (1991) travel time estimates are determined and used to determine which products (fast moving, slow moving) should be located 
in which aisles. Le-Duc and De Koster (2004) develop similar travel time estimates for the return heuristic. A travel time analysis for a general product-to-location assignment is given in Chew and Tang (1999) and Tang and Chew (1997). That is, demand rates for products can vary throughout the warehouse. They use the travel time estimates to evaluate batching strategies. Expected travel distances for two routing methods in a warehouse consisting of two blocks are given in Caron et al. (1998). They locate the depot between the two blocks and items are assumed to be distributed according to the cube-per-order index. Hwang et al. (2004) present analytical expressions for three routing methods (return, S-shape, midpoint) under various COI-based storage rules.

\section{Order accumulation and sorting}

When batching and/or zoning is applied, usually some additional effort is needed to split the batch and to consolidate the items per customer order or per destinations to which orders will be shipped. These processes are often called accumulation/sorting (A/S).

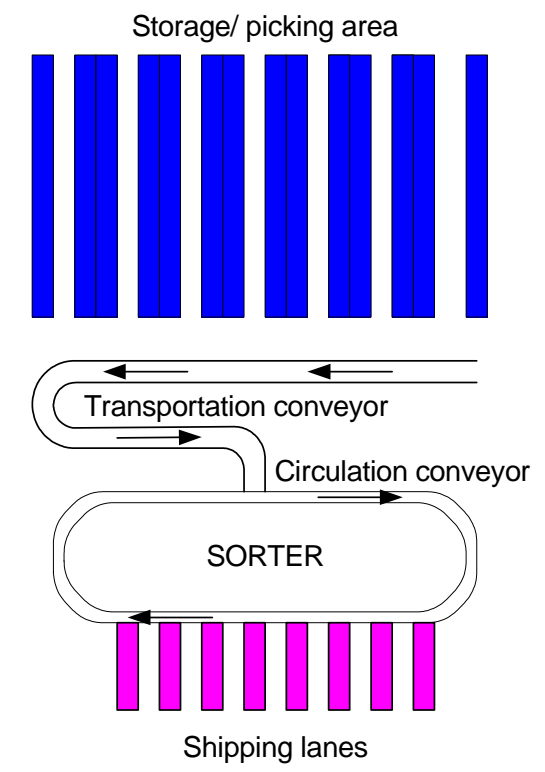

Figure 9 A typical accumulation/sorting (A/S) system

Figure 9 shows an example of a typical A/S system (mentioned in Meller, 1997 and Johnson, 1998). Items of a group of orders (a pick-wave) that are to be loaded onto a certain number of trucks are picked from the picking area. In general, items from the same order are assigned to multiple order pickers (to maintain high order picker efficiency) and the order pickers follow pre-specified routes to pick the items assigned to them. After picking, order pickers place their items on the transportation conveyor and the items are transported to the sorter. Owing to the assignment of orders to more than one order picker, the items of each order arrive at the sorter in a random sequence. Items are released onto the circulation conveyor of the sorter and enter the assigned shipping lane if all items of the preceding order assigned to that lane have already entered. If not, the items re-circulate around the circulation conveyor. Orders are released from shipping lanes as needed by the trucks and the lane capacity is made available for the next sort-group. The throughput of an A/S system depends not only on the equipment capacity (i.e. sorter capacity and conveyor speed) but also on operating policies like assignment of orders to shipping lanes (see Figure 9). The order-to-lane assignment problem is 
critical for most A/S systems as usually the number of shipping lanes is less than the number of orders, which may cause a blocking of orders at the entrance of the lanes.

The number of publications on A/S systems is limited. By simulation, Bozer and Sharp (1985) examine advantages of using a recirculation loop to avoid lane blocking in an A/S system when a shipping lane is full, assuming that each lane is assigned to one order. Considering A/S systems where multiple orders can be are assigned to one lane, Bozer et al. (1988) and Johnson (1998) recommend that assigning orders to shipping lanes just before the orders arrive at the circulation desk of the sorter is a better than any static fixedassignment rule. Johnson and Lofgren (1994) describe an A/S system used at Hewlett-Packard. Meller (1997) proposes an integer formulation for the order-to-lane assignment problem in an A/S system. He claims that the problem can be solved efficiently for small instances (in terms of the number of lanes) by solving a number of minimum-cardinality sub-problems. Russell and Meller (2003) present a model to aid in the decision whether or not to automate the sorting process. Le-Duc and De Koster (2005a) present an integer-programming model to minimise the total picking and order accumulation time. Although the general problem is NP-hard, it solves to optimality in reasonable time for a real-life problem.

\section{Conclusions}

We can draw the following conclusions from the literature. First, in spite of their dominance in practice, pickers-to-parts order-picking systems have received less research attention compared to parts-to-picker order-picking systems. Less than 30 percent of the about 140 papers we considered concerns pickers-to-part order-picking systems. The reasons for this may have something to do with the complexity and diversity of picker-to-parts order-picking systems. Furthermore, parts-to-picker systems are often fully or partly automated, thus catch the attention of researchers.

Second, although the number of publications in the areas of layout, batching, zoning, storage strategies (like forward-reserve allocation, family grouping, and dynamic storage), and accumulation and sorting is still limited, their number is growing. Particularly, the areas of storage assignment and routing appear to have matured the last decade. Few authors address combinations of the decision problems. Yet, this is necessary as there is obvious interdependency in their impact on the order picking objectives. New developments in practice yielding unprecedented picker productivities like dynamic storage and put (order distribution) systems have not yet led to attention from academics.

Third, existing studies in picker-to-parts order-picking systems mainly focus on random storage assignments. Analytical models for optimising dedicated and class-based storage assignment manual-pick order-picking systems are still lacking. Furthermore, storage assignment has an impact on the performance of the routing method. However, this effect seems to be largely neglected in the literature. Instead, many authors focus on random storage assignment to discus about the performance of routing methods.

Fourth, almost all research in order picking treats demand as given (or known in advance). Certainly, this is not true, especially in fast picking environments (e.g. small orders arrive on line and need to be shipped within a tight time window). These order-picking situations are becoming more and more daily practice, particularly for mail order companies which sell products online. Optimisation problems arising from these order-picking systems, therefore, should be considered as stochastic optimisation problems, not deterministic ones.

Finally, most of the research focuses on a specific order picking situation or decision problem. However, it is not straight forward to apply methods developed for a specific situation to another situation. 'General' design procedures and 'global' optimisation models for order picking are still lacking. 


\section{References}

Apte, U.M. and Viswathan, S., Effective cross docking for improving distribution efficiencies. International Journal of Logistics: Research and Applications, 2000, 3(3), 291-302.

Ashayeri, J. and Gelders, L.F., Warehouse design optimization. European Journal of Operational Research, 1985, 21, 285-294.

Bartholdi, J.J., Balancing two-sided assembly lines: a case study, International Journal of Production Research, 1993, 31(10), 2447-2461.

Bartholdi, J., Bunimovich, L.A. and Eisenstein, D., Dynamics of two- and three-worker "bucket brigade" production lines. Operations Research, 1999, 47(3), 488-491.

Bartholdi, J. and Eisenstein, D., Bucket brigades: a self-organizing order-picking system for a warehouse, Report, School of Industrial Engineering, Georgia Tech, Atlanta, USA, 1996.

Bartholdi, J. and Eisenstein, D., Bucket brigades). Available on line at: http://www.isye.gatech.edu/ jjb/bucket-brigades.html (Accessed May 2005a).

Bartholdi, J. and Eisenstein, D., Using bucket brigades to migrate from craft manufacturing to assembly lines. Management Science and Operations Management, 2005b (to appear).

Bartholdi, J., Eisenstein, D. and Foley, R., Performance of bucket brigades when work is stochastic. Operations Research, 2001, 49(5), 710-719.

Bartholdi, J., Eisenstein, D. and Lim, Y.F., Bucket brigades on in-tree assembly networks. European Journal of Operational Research, 2005 (to appear).

Bartholdi, J. J. and Hackman, S. T., Warehouse \& distribution science. Available on line at: http://www.tli.gatech.edu/whscience/ book/wh-sci.pdf (Accessed May 2005).

Bassan, Y., Roll, Y. and Rosenblatt, M.J., Internal layout design of a warehouse. AIIE Transactions, 1980, 12(4), 317-322.

Bozer, Y.A., and Cho, M., Throughput performance of automated storage/retrieval systems under stochastic demand, IIE Transactions, 2005, 37(4), 367-378.

Bozer, Y.A., Quiroz, M.A. and Sharp, G.P., An evaluation of alternative control strategies and design issues for automated order accumulation and sortation systems. Material Flow, 1988, 4, 265-282.

Bozer, Y.A. and Sharp, G.P., An empirical evaluation of general purpose automated order accumulation and sortation system used in batch picking. Material Flow, 1985, 2, 111-113.

Bozer, Y.A. and White, J.A., Travel-time models for automated storage/retrieval systems. IIE Transactions, 1984, 16, 329-338.

Brynzér, H., and Johansson, M.I., Design and performance of kitting and order picking systems, International Journal of Production Economics, 1995, 41, 115-125.

Brynzér, H. and Johansson, M.I., Storage location assignment: using the product structure to reduce order picking times. International Journal of Production Economics, 1996, 46, 595-603.

Caron, F., Marchet, G. and Perego, A., Routing policies and COI-based storage policies in picker-to-part systems. International Journal of Production Research, 1998, 36(3), 713-732. 
Caron, F., Marchet, G. and Perego, A., Optimal layout in low-level picker-to-part systems. International Journal of Production Research, 2000, 38(1), 101-117.

Chen, M.C., Huang, C.L., Chen, K.Y., and Wu, H.P., Aggregation of orders in distribution centers using data mining, Expert Systems with Applications, 2005, 28(3), 453-460.

Chen, M.C., and Wu, H.P., An association-based clustering approach to order batching considering customer demand patterns, Omega International Journal of Management Science, 2005, 33(4), 333-343.

Chew, E.P. and Tang, L.C., Travel time analysis for general item location assignment in a rectangular warehouse. European Journal of Operational Research, 1999, 112, 582-597.

Choe, K. and Sharp, G. P., Small parts order picking: design and operation. Available on-line at: http://www.isye.gatech.edu/logisticstutorial/order/article.htm, 1991 (Accessed May 2005).

Choe, K., Sharp, G.P. and Serfozo, R.S., Aisle-based order pick systems with batching, zoning and sorting, in Progress in Material Handling Research: 1992, 1993, 245-276.

Clarke, G. and Wright, W., Scheduling of vehicles from a central depot to a number of delivery points, Operations Research, 1964, 12, 568-581.

Cormier, G., A brief survey of operations research models for warehouse design and operation, Report, Bulletin, CORS-SCRO, 1997.

Cormier, G. and Gunn, E.A., A review of warehouse models. European Journal of Operational Research, 1992, 58, 3-13.

Cornuéjols, G., Fonlupt, J., and Naddef, D., The traveling salesman problem on a graph and some related integer polyhedra, Mathematical Programming, 1985, 33, 1-27.

Daniels, R.L., Rummel, J.L. and Schantz, R., A model for warehouse order picking. European Journal of Operational Research, 1998, 105, 1-17.

De Koster, R., Performance approximation of pick-to-belt orderpicking systems. European Journal of Operational Research, 1994, 72, 558-573.

De Koster, R., How to assess a warehouse operation in a single tour, Report, RSM Erasmus University, the Netherlands, 2004.

De Koster, R. De Brito, M.P. and Van de Vendel, M., Return handling: An exploratory study with nine retailer warehouses, International Journal of Retail \& Distribution Management, 2002, 30(8/9); 407-421.

De Koster, R. and T. Le-Duc, Single-command travel time estimation and optimal rack design for a 3-dimensional compact AS/RS, in R. Meller, M.K. Ogle, B.A. Peters, G.D. taylor, J. Usher (eds.), Progress in Material Handling Research: 2004, 2005, 49-66, (Material Handling Institute, Charlotte).

De Koster, R. and Neuteboom, A.J,, The logistics of supermarket chains, 2001 (Elsevier, Doetinchem).

De Koster, R., Roodbergen, K.J. and Van Voorden, R., Reduction of walking time in the distribution center of De Bijenkorf, in M.G. Speranza, P Stähly (eds.), New Trends in Distribution Logistics, 1999a, 215-234 (Berlin: Springer).

De Koster, R. and Van der Poort, E.S., Routing orderpickers in a warehouse: a comparison between optimal and heuristic solutions. IIE Transactions, 1998, 30, 469-480.

De Koster, R., Van der Poort, E.S. and Roodbergen, K.J., When to apply optimal or heuristic routing for orderpickers, in B. Fleischmann, J.A.E.E. van Nunen, M.G. Speranza, P. Stähly (eds.), Advances in Distribution Logistics, 1998, 375-401 (Berlin: Springer). 
De Koster, R., Van der Poort, E.S. and Wolters, M., Efficient orderbatching methods in warehouses. International Journal of Production Research, 1999b, 37(7), 1479-1504.

Dekker, R., de Koster, R., Roodbergen, K.J. and Van Kalleveen, H., Improving order-picking response time at Ankor's warehouse. Interfaces, 2004, 34(4), 303-313.

Drury, J., Towards more efficient order picking, IMM Monograph No. 1, Report, The Institute of Materials Management, Cranfield, U.K., 1988.

ELA/AT Kearney, Excellence in logistics 2004, 2004, (Brussels: ELA)..

Elsayed, E.A., Algorithms for optimal material handling in automatic warehousing systems. International Journal of Production Research, 1981, 19(5), 525-535.

Elsayed, E.A. and Lee, M.K., Order processing in automated storage/retrieval systems with due dates. International Journal of Production Research, 1996, 28(7), 567-577.

Elsayed, E.A., Lee, M.K., Kim, S. and Scherer, E., Sequencing and batching procedures for minimizing earliness and tardiness penalty or order retrievals. International Journal of Production Research, 1993, 31(3), 727-738.

Elsayed, E.A. and Stern, R.G., Computerized algorithms for order processing in automated warehousing systems. International Journal of Production Research, 1983, 21(4), 579-586.

Elsayed, E.A. and Unal, O.I., Order batching algorithms and travel-time estimation for automated storage/retrieval systems. International Journal of Production Research, 1989, 27, 1097-1114.

Francis, R.L., On some problems of rectangular warehouse design and layout, Journal of Industrial Engineering, 1967, 18(10), 595604.

Frazelle, E.H. Hackman, S.T., Passy, U., and Platzman, L.K., The forward-reserve problem, in: T.C. Ciriani, R.C. Leachman (eds), Optimization in industry 2, 1994, 43-61 (Wiley: New York).

Frazelle, E.A. and Sharp, G.P., Correlated assignment strategy can improve order-picking operation. Industrial Engineering, 1989, 4, 33-37.

Gademann, A.J.R.N., Van den Berg, J.P. and Van der Hoff, H.H., An order batching algorithm for wave picking in a parallel-aisle warehouse. IIE Transactions, 2001, 33, 385-398.

Gademann, N. and Van de Velde, S., Batching to minimize total travel time in a parallel-aisle warehouse. IIE Transactions, 2005, 37(1), 63-75.

Gibson, D.R. and Sharp, G.P., Order batching procedures. European Journal of Operational Research, 1992, 58(1), 57-67.

Goetschalckx, M. and Ashayeri, J., Classification and design of order picking systems. Logistics World, 1989, June, 99-106.

Goetschalckx, M. and Ratliff, D.H., An efficient algorithm to cluster order picking items in a wide aisle. Engineering Costs and Production Economy, 1988a, 13, 263-271.

Goetschalckx, M. and Ratliff, D.H., Order picking in an aisle. IIE Transactions, 1988b, 20, 531-562.

Goetschalckx, M. and Wei, R., Bibliography on order picking systems, Vol. 1: 1985-1992. Available on line at: http://www.isye. gatech.edu/ people/ faculty/Marc_Goetschalckx/research.html (Accessed May 2005).

Graves, S.C., Hausman, W.H. and Schwarz, L.B., Storage-retrieval interleaving in automatic warehousing systems. Management Science, 1977, 23, 935-945. 
Guenov, M. and Raeside, R., Zone shape in class based storage and multicommand order picking when storage/retrieval machines are used. European Journal of Operational Research, 1992, 58(1), 37-47.

Hackman, S.T. and Platzman, L.K., Near optimal solution of generalized resource allocation problems with large capacities. Operations Research, 1990, 38(5), 902-910.

Hall, R.W., Distance approximation for routing manual pickers in a warehouse. IIE Transactions, 1993, 25, 77-87.

Hausman, W.H., Schwarz, L.B. and Graves, S.C., Optimal storage assignment in automatic warehousing systems. Management Science, 1976, 22(6), 629-638.

Heragu, S.S., Du, L., Mantel, R.J., and Schuur, P.C., Mathematical model for warehouse design and product allocation, International Journal of Production Research, 2005, 43(2), 327-338.

Heskett, J.L., Cube-per-order index - a key to warehouse stock location. Transport and Distribution Management, 1963, 3, 27-31.

Heskett, J.L., Putting the cube-per-order index to work in warehouse layout. Transport and Distribution Management, 1964, 4, 2330.

Hsu, C.M., Chen, K.Y., and Chen, M.C., Batching orders in warehouses by minimizing travel distance with genetic algorithms, Computers in Industry, 2005, 56(2), 169-178.

Hwang, H., Baek, W. and Lee, M., Cluster algorithms for order picking in an automated storage and retrieval system. International Journal of Production Research, 1988, 26, 189-204.

Hwang, H. and Lee, M.K., Order batching algorithms for a man-on-board automated storage and retrieval system. Engineering Costs and Production Economics, 1988, 13, 285-294.

Hwang, H., Oh, Y.H., and Lee, Y.K., An evaluation of routing policies for order-picking operations in low-level picker-to-part system, International Journal of Production Research, 2004, 42(18), 3873-3889.

Jane, C.C., Storage location assignment in a distribution center. International Journal of Physical and Logistics Management, 2000, 30(1), 55-71.

Jane, C.C. and Laih, Y.W., A clustering algorithm for item assignment in a synchronized zone order picking system. European Journal of Operational Research, 2005 (to appear).

Jarvis, J.M. and McDowell, E.D., Optimal product layout in an order picking warehouse. IIE Transactions, 1991, 23(1), 93-102.

Jewkes, E., Lee, C. and R. Vickson, Product location, allocation and server home base location for an order picking line with multiple servers, Computers \& Operations Research, 2004, 31, 623-626.

Johnson, M.E., The impact of sorting strategies on automated sortation system performance. IIE Transactions, 1998, 30, 67-77.

Johnson, M.E. and Brandeau, M.L., Stochastic modeling for automated material handling system design and control. Transportation Science, 1996, 30(4), 330-350.

Johnson, M.E. and Lofgren, T., Model decomposition speeds distribution center design. Interfaces, 1994, 24(5), 95-106.

Kallina, C. and Lynn, J., Application of the cube-per-order index rule for stock location in a distribution warehouse. Interfaces, 1976, 7 (1), 37-46.

Kunder, R., and Gudehus, T., Mittlere Wegzeiten beim eindimensionalen Kommissionieren, Zeitschrift für Operations Research, 19, 1975, B53-B72. 
Lambert, D.M., Stock, J.R. and Ellram, L.M. (Ed.), Fundamentals of logistics management, 1998 (Singapore: McGraw-Hill).

Larson, T.N., March, H. and Kusiak, A., A heuristic approach to warehouse layout with class based storage. IIE Transactions, 1997, 29, 337-348.

Lawler, E.L., Lenstra, J.K., Rinnooy Kan, A.H.G., and Shmoys, D.B., The traveling salesman problem, 1995, (Chichester: Wiley).

Le-Duc, T., Design and control of efficient order picking processes, PhD thesis, RSM Erasmus University, 2005.

Le-Duc, T. and De Koster, R., An approximation for determining the optimal picking batch size for order picker in single aisle warehouses, in R. Meller, M.K. Ogle, B.A. Peters, G.D. taylor, J. Usher (eds.), Progress in Material Handling Research: 2002, 2003a, 267-286.

Le-Duc, T. and De Koster, R., Travel time estimation and order batching in a 2-block warehouse, 2003b, to appear in European Journal of Operational Research.

Le-Duc, T. and De Koster, R., Travel distance estimation in a single-block ABC storage strategy warehouse, in B. Fleischmann and B. Klose (eds.) Distribution Logistics: advanced solutions to Practical Problems, 2004, 185-202, (Berlin: Springer).

Le-Duc, T. and De Koster, R., Determining the optimal number of zones in a pick-and-pack order picking system, Report ERS2005-029-LIS, RSM Erasmus University, the Netherlands, 2005a.

Le-Duc, T. and De Koster, R., Layout optimization for class-based storage strategy warehouses, in Supply Chain Management European Perspective, 2005b, 191-214.

Le-Duc, T. and De Koster, R., Travel distance estimation and storage zone optimisation in a 2-block class-based storage strategy warehouse. International Journal of Production Research, 2005c, 43(17), 3561-3581.

Lee, M.K., A storage assignment policy in a man-on-board automated storage/retrieval system. International Journal of Production Research, 1992, 30(10), 2281-2292.

Lin, S., Kernighan, B.W., An effective heuristic algorithm for the traveling salesman problem. Operations Research, 1973, 21(2) 498-516.

Liu, C.M., Clustering techniques for stock location and order-picking in a distribution center. Computers and Operations Research, 1999, 26, 989-1002.

Makris, P.A., and Giakoumakis, I.G., k-interchange heuristic as an optimization procedure for material handling applications, Applied Mathematical Modelling, 2003, 27(5), 345-358.

Malmborg, C.J., Optimization of Cubic-per-Order Index layouts with zoning constraints. International Journal of Production Research, 1995, 33(2), 465-482.

Malmborg, C.J., Storage assignment policy tradeoffs. International Journal of Production Research, 1996, 34(2), 363-378.

Malmborg, C.J. and Bhaskaran, K., On the optimality of the cube per order index for conventional warehouses with dual command cycles. Material Flow, 1987, 4, 169-175.

Malmborg, C.J. and Bhaskaran, K., Optimal storage assignment policies for multiaddress warehousing systems. IEEE Transactions on Systems, Man and Cybernetics, 1989, 19(1), 197-204.

Malmborg, C.J. and Bhaskaran, K., A revised proof of optimality for the cube-per-order index rule for stored item location. Applied Mathematical Modelling, 1990, (14), 87-95.

Mellema, P.M. and Smith, C.A., Simulation analysis of narrow-aisle order selection systems. Proceedings of the 1988 Winter 
Simulation Conference, 1988, 597-602.

Meller, R.D., Optimal order-to-lane assignments in an order accumulation/sortation system. IIE Transactions, 1997, 29(4), 293301.

Meller, R.D. and Gau, K.Y., The facility layout problem: recent and emerging trends and perspectives. Journal of Manufacturing Systems, 1996, 15(5), 351-366.

Pan, C.H. and Liu, S.Y., A comparative study of order batching algorithms. Omega International Journal of Management Science, 1995, 23(6), 691-700.

Pandit, R., and Palekar, U.S., Response time considerations for optimal warehouse layout design, Journal of Engineering for Industry, 1993, 115, 322-328.

Park, Y.H. and Webster, D.B., Design of class-based storage racks for minimizing travel time in a three dimensional storage system. International Journal of Production Research, 1989, 27(9), 1589-1601.

Petersen, C.G., Routeing and storage policy interaction in order picking operations. Decision Sciences Institute Proceedings, 1995, 3, 1614-1616.

Petersen, C.G., An evaluation of order picking routing policies. International Journal of Operations \& Production Management, 1997, 17(11), 1098-1111.

Petersen, C.G., The impact of routing and storage policies on warehouse efficiency. International Journal of Operations \& Production Management, 1999, 19(10), 1053-1064.

Petersen, C.G., An evaluation of order picking policies for mail order companies. Production and Operations Management, 2000, 9(4), 319-335.

Petersen, C.G., Considerations in order picking zone configuration. International Journal of Operations \& Production Management, 2002, 27(7), 793-805.

Petersen, C.G. and Aase, G., A comparison of picking, storage, and routing policies in manual order picking. International Journal of Production Economics, 2004, 92, 11-19.

Petersen, C.G., Aase, G. and Heiser, D.R., Improving order-picking performance through the implementation of class-based storage. International Journal of PhysicalDistribution \& Logistics Management, 2004, 34(7), 534-544.

Petersen, C.G. and Schmenner, R.W., An evaluation of routing and volume-based storage policies in an order picking operation. Decision Sciences, 1999, 30(2), 481-501.

Ratliff, H.D. and Rosenthal, A.S., Orderpicking in a rectangular warehouse: a solvable case of the traveling salesman problem. Operations Research, 1983, 31(3), 507-521.

Roll, Y. and Rosenblatt, M.J., Random versus grouped storage policies and their effect on warehouse capacity. Material Flow, 1983, 1, 199-205.

Roodbergen, K.J., Layout and routing methods for warehouses, PhD thesis, RSM Erasmus University, the Netherlands, 2001.

Roodbergen, K.J., Storage assignment policies for warehouses with multiple cross aisles, in R. Meller, M.K. Ogle, B.A. Peters, G.D. taylor, J. Usher (eds.), Progress in Material Handling Research: 2004, 2005, 541-560.

Roodbergen, K.J. and De Koster, R., Routing methods for warehouses with multiple cross aisles. International Journal of Production Research, 2001a, 39(9), 1865-1883. 
Roodbergen, K.J. and De Koster, R., Routing order-pickers in a warehouse with a middle aisle, European Journal of Operational Research, 2001b, 133, 32-43.

Rosenblatt, M.J. and Roll, Y., Warehouse design with storage policy considerations. International Journal of Production Research, 1984, 22(5), 809-821.

Rosenblatt, M.J. and Roll, Y., Warehouse capacity in a stochastic environment. International Journal of Production Research, 1988, 26(12), 1847-1851.

Rosenwein, M.B., An application of cluster analysis to the problem of locating items within a warehouse. IIE Transactions, 1994, 26(1), 101-103.

Rouwenhorst, B., Reuter, B., Stockrahm, V., van Houtum, G.J., Mantel, R.J. and Zijm, W.H.M., Warehouse design and control: framework and literature review. European Journal of Operational Research, 2000, 122, 515-533.

Ruben, R.A. and Jacobs, F.R., Batch construction heuristics and storage assignment strategies for walk/ride and picking systems. Management Science, 1999, 45(4), 575-596.

Russell, M.L., and Meller, R.D., Cost and throughput modelling of manual and automated order fulfilment systems, IIE Transactions, 2003, 35(7), 589-603.

Sarker, B.R. and Babu, P.S., Travel time models in automated storage/retrieval systems: a critical review. International Journal of Production Economics, 1995, 40, 173-184.

Speaker, R.L., Bulk order picking, Industrial Engineering, 1975, 7(12), 14-18.

Tang, L.C. and Chew, E.P., Order picking systems: batching and storage assignment strategies. Computer \& Industrial Engineering, 1997, 33(3), 817-820.

Thonemanm, U.W. and Brandeu, M.L., Optimal storage assignment policies for automated storage and retrieval systems with stochastic demands. Management Science, 1998, 41(1), 142-148.

Tompkins, J.A., White, J.A., Bozer, Y.A., Frazelle, E.H. and Tanchoco, J.M.A., Facilities Planning, 2003 (NJ: John Wiley \& Sons).

Van den Berg, J.P., A literature survey on planning and control of warehousing systems. IIE Transactions, 1999, 31, 751-762.

Van den Berg, J.P. and Gademann, A.J.R.N., Simulation study of an automated storage/retrieval system. International Journal of Production Research, 2000, 38, 1339-1356.

Van den Berg, J.P., Sharp, G.P.G.A.J.R.N. and Pochet, Y., Forward-reserve allocation in a warehouse with unit-load replenishments. European Journal of Operational Research, 1998, 111, 98-113.

Van den Berg, J.P. and Zijm, W.H.M., Models for warehouse management: classification and examples. International Journal of Production Research, 1999, 59, 519-528.

Van Hoek, R.I., The rediscovery of postponement a literature review and directions for research, Journal of Operations Management, 2001, 19(2), 161-184.

Van Oudheusden, D.L., Tzen, Y.J. and Ko, H., Improving storage and order picking in a person-on-board AS/R system. Engineering Costs and Production Economics, 1988, 13(4), 273-283.

Van Oudheusden, D.L. and Zhu, W., Storage layout of AS/RS racks based on recurrent orders. European Journal of Operational Research, 1992, 58(1), 48-56. 
Vaughan, T.S. and Petersen, C.G., The effect of warehouse cross aisles on order picking efficiency. International Journal of Production Research, 1999, 37(4), 881-897.

Wäscher, G., Order picking: a survey of planning problems and methods, in Supply chain management and reverse logistics, 2004, 323-347.

Won, J., and Olafsson, S., Joint order batching and order picking in warehouse operations, International Journal of Production Research, 2005, 43(7), 1427-1442.

Yang, M.H., Analysis of optimization of class-based dedicated storage systems, Report, Material Handling Research Center, Georgia Institute of Technology, Atlanta, Georgia, 1988.

\section{Online sources}

Erasmus-Logistica warehouse design, http://www.fbk.eur.nl//OZ/LOGISTICA (online since 1998, accessed 2005) 


\section{Publications in the Report Series Research* in Management}

\section{ERIM Research Program: "Business Processes, Logistics and Information Systems"}

2006

Smart Business Networks Design and Business Genetics

L-F Pau

ERS-2006-002-LIS

Designing and Evaluating Sustainable Logistics Networks

J. Quariguasi Frota Neto, J.M. Bloemhof-Ruwaard, J.A.E.E. van Nunen and H.W.G.M. van Heck ERS-2006-003-LIS

Design and Control of Warehouse Order Picking: a literature review

René de Koster, Tho Le-Duc and Kees Jan Roodbergen

ERS-2006-005-LIS

A Theoretical Analysis of Cooperative Behavior in Multi-agent Q-learning

Ludo Waltman and Uzay Kaymak

ERS-2006-006-LIS

Supply-Chain Culture Clashes in Europe. Pitfalls in Japanese Service Operations

M.B.M. de Koster and M. Shinohara

ERS-2006-007-LIS

* A complete overview of the ERIM Report Series Research in Management: https://ep.eur.nl/handle/1765/1

ERIM Research Programs:

LIS Business Processes, Logistics and Information Systems

ORG Organizing for Performance

MKT Marketing

F\&A Finance and Accounting

STR Strategy and Entrepreneurship 